\title{
Privacy Protections and Law Enforcement Use of Prescription Drug Monitoring Databases ${ }^{1}$
}

\author{
Anne E. Boustead \\ 315 Social Sciences Bldg. \\ P.O. Box 210027 \\ Tucson, AZ 85721 \\ (520) 621-3574 \\ boustead@email.arizona.edu
}

Biographical Statement: Anne Boustead is an assistant professor in the School of Government \& Public Policy at the University of Arizona, where she studies legal and policy issues related to electronic surveillance, privacy, policing, and drug policy.

\footnotetext{
${ }^{1}$ The author wishes to express her gratitude for the invaluable feedback received from participants and discussants at the 2018 Privacy Law Scholars Conference (particularly Alan Rubel), the University of Arizona James E. Rodgers College of Law Lunchtime Enrichment Series, the 2018 Utah Law Review Symposium, and the Research Roundtable for Scholars workshop hosted by the Program on Economics \& Privacy (George Mason University Antonin Scalia Law School/University of Arizona James E. Rogers College of Law). All remaining errors are, of course, my own.
} 


\begin{abstract}
Prescription drug monitoring programs (PDMPs) are databases designed to help healthcare professionals identify problematic drug-seeking behavior from patients. PDMPs can also be used by police officers to obtain evidence, raising concerns about exposure of sensitive health information. In this paper, I describe the approaches that states have taken to regulate law enforcement access to PDMPs, and present evidence that some but not all protection mechanisms are associated with fewer law enforcement requests for PDMP information. This research provides novel and important information about law enforcement behavior in response to privacy protections.
\end{abstract}


As the social harms due to opioid misuse have skyrocketed over the past two decades (Rudd, Aleshire et al. 2016), policymakers have struggled to formulate an appropriate response to this crisis. As part of this effort, 49 states have implemented prescription drug monitoring programs (PDMPs). PDMPs are a decades-old tool meant to prevent improper prescribing and use of controlled substances by establishing “centralized database[s]....to which pharmacies report dispensed medications (by drug name, strength, and quantity), date, prescriber, and patient” (Deyo, Irvine et al. 2013). The resulting database can be used to identify individuals with multiple overlapping opioid prescriptions from different physicians, a potential sign of non-medical use. While they were originally intended as a mechanism for policing controlled substances, in recent years PDMPs have been hailed as part of the new "public health" approach to addressing the growing opioid crisis (Haffajee 2015).

While some policymakers have embraced PDMPs as a tool for preventing opioid misuse, these programs raise significant privacy concerns. PDMPs contain records on hundreds of millions of prescriptions, and are designed to allow the user to track medical information for a particular individual over time and across providers. In many states, the prescriptions that must be reported to PDMPs include not only opioid painkillers with high addictive potential, but also drugs with much lower potential for abuse (DEA 2018). Knowledge about a person's use of these drugs allows inferences about a wide range of highly sensitive medical information, including whether a person is undergoing hormone replacement therapy, being treated for a variety of mental illnesses, or their HIV status (Mejia 2014). Furthermore, the majority of states allow law enforcement to access to 
PDMP data without first demonstrating probable cause to a neutral magistrate, instead relying on a variety of less stringent mechanisms to protect the significant privacy interests at stake.

Variation in state protections for PDMP information provide a rare opportunity to explore whether requiring law enforcement to obtain a warrant or subpoena prior to pursuing evidence impacts whether and how they seek information. Despite the doctrinal and normative importance of using justification standards such as the warrant requirement to regulate law enforcement use of surveillance, there is currently very little empirical evidence on whether and under what conditions these standards change law enforcement behavior. Furthermore, no studies have explored variation in response to the warrant requirement across different types of agencies, even though law enforcement agencies vary greatly in the resources they can leverage to pursue surveillance.

In this paper, I examine state efforts to regulate law enforcement access to PDMP data. My goal is two-fold: first, to explore variation in PDMP protections across states, and second to analyze whether this variation is associated with different levels of law enforcement use of PDMP information. I start with a general overview of both the legal and non-legal mechanisms that can be used to limit law enforcement access to information, and the prior literature on how law enforcement behavior may or may not change in response to these mechanisms. I then describe state PDMP programs, focusing on how much data is aggregated by these programs and how the resulting data can be used. Next, I describe how states have regulated law enforcement access to PDMP data, arguing that state statutory law plays a particularly important role in this regulatory 
process. I then quantitatively analyze administrative data describing the yearly number of law enforcement requests for PDMP information across the country, as well as substate data from Utah. This analysis focuses on addressing two main questions. First, does law enforcement use of PDMP data vary based on the legal protections afforded to that data under state statutes? Second, based on evidence from Utah, do the observed differences before and after the imposition of a warrant requirement vary based on agency or locality characteristics? I then conclude by discussing the implications of my findings for the regulation of law enforcement access to information.

\section{Regulating Law Enforcement Access to Information}

Under Supreme Court precedent, the Fourth Amendment's protection of " $[t]$ he right of the people to be secure in their persons, houses, papers, and effects, against unreasonable searches and seizures" (U.S. Const. Amend. IV) is implemented through privacy interests: whenever the government engages in activities that violate an individual's reasonable expectation of privacy, they are conducting a Fourth Amendment search and generally must first obtain a warrant based on probable cause (Katz v. United States, 389 U.S. 347 (1967)). In practice, many mechanisms commonly used by law enforcement to obtain information fall outside of the doctrinal definition of a search, and consequently outside of Fourth Amendment protections. For example, under the third party doctrine, federal jurisprudence long excluded information about individuals collected by commercial service providers from Constitutional protection, holding that Fourth Amendment protections do not extend to information an individual voluntarily 
provides to others, "even if the information is revealed on the assumption that it will be used only for a limited purpose and the confidence placed in the third party will not be betrayed" (U.S. v. Miller, 425 U.S. 435, 443 (1976)).

Technological innovations allowing law enforcement access to new sources of information continuously challenge - and sometimes change - interpretation of the Fourth Amendment. For example, recent Supreme Court case law refused to extend the third party doctrine to law enforcement use of cell site location information (CSLI), holding instead that "an individual maintains a legitimate expectation of privacy in the record of his physical movements as captured through CSLI." (585 U.S.__ at 11) The majority opinion explicitly noted that, in contrast to prior mechanisms for tracking a suspect's location, cell site location records allow law enforcement to obtain location information with virtually no cost, and to obtain information retrospectively. (585 U.S. at 12-3)

Supreme Court jurisprudence also defines numerous circumstances under which law enforcement can conduct a search without first obtaining a warrant. Although the Supreme Court has described these exclusions as "a few specifically established and well-delineated exceptions" (Katz v. U.S., 389 U.S. at 357), in practice the vast majority of law enforcement searches are conducted without a warrant (Israel 1971, Slobogin 2003). However, even if law enforcement is not required to obtain a warrant, they may still be required to provide other justification for their behavior. Similarly, legislatures can elect to limit law enforcement access to information through statute, without requiring that law enforcement demonstrate probable cause (Ohm 2009). For example, 
under the Stored Communications Act, law enforcement can obtain access to basic information about the user of an account with an administrative subpoena (18 U.S.C. $\S$ 2703(c)(2)).

Legal constraints are not the only mechanisms that limit law enforcement access to information. While the time, cost, and difficulty of obtaining information has long provided an important check on law enforcement information collection (U.S. v. Jones, 132 S.Ct. 945, 963 (2012)), these limitations have only become salient as new forms of electronic surveillance allow law enforcement to gather information quickly, cheaply, and easily. The theoretical mechanism through which cost impacts law enforcement use of surveillance is straight-forward: if law enforcement officers act as rational economic actors, they should seek out information where they expect that the benefits of having the information would outweigh the costs associated with acquiring it. As the cost of surveillance decreases, law enforcement should be willing to engage in surveillance where they are less certain that they will obtain useful information - and consequently individuals may be subjected to surveillance with less preliminary evidence that they are connected to criminal activity.

Furthermore, different kinds of costs may have different impacts on law enforcement's decision to seek information. Some expenses related to obtaining information operate as fixed costs, not varying with the amount of information obtained, while other expenses may operate as variable costs, increasing as the amount of information obtained increases. For example, necessary equipment purchases or training prior to conducting surveillance might be considered a fixed cost, while manpower or 
requests for legal permission might be considered a variable cost (since they must be expended every time law enforcement seeks information). Fixed costs may "be expected to have a binary effect on law enforcement surveillance decision-making": as a law enforcement agency must decide whether to opt-in by paying the cost, but once the cost has been paid they may collect a large amount of information (Boustead 2016). In contrast, variable costs effect every unit of surveillance utilized and consequently should be expected to have a continual effect on surveillance use. In other words, fixed costs affect an agency's or officer's capacity to conduct surveillance, while variable costs affect the amount of surveillance used.

Under this model, legal requirements for obtaining surveillance can be seen as imposing a special type of cost, based on the resources that must be expended to develop evidence and complete administrative requirements. Consequently, courts can use legal standards as a corrective mechanism when new technologies dramatically reduce the cost of conducting surveillance, ensuring that the ability of the government to obtain information remains stable relative to the individual's ability to conceal it (Kerr 2011) and that law enforcement does not engage in patterns of surveillance that inconvenience large numbers of innocent people (Bambauer 2014). For example, Bankston and Soltani argue that application of the Fourth Amendment to emerging forms of technological surveillance should depend on the change in the cost of obtaining information: "[i]f the cost of the surveillance using the new technique is an order of magnitude (ten times) less than the cost of the surveillance without using the new technique, then the new technique 
violates a reasonable expectation of privacy" and consequently implicates the target's Fourth Amendment rights (Bankston and Soltani 2013).

Although it may seem obvious that increasing the protections provided to information will reduce the frequency with which law enforcement requests information, there is currently little empirical evidence whether - and under what circumstances - law enforcement use of surveillance changes in response to changes in legal requirements or cost. Minzner and Anderson (2013) used formal economic modeling to argue that the warrant requirement does not impose a constraint on law enforcement use of wiretaps rather, the time and expense required ensures that law enforcement will only seek to use wiretaps under circumstances where the probability of successfully obtaining evidence is greater than that required for probable cause. Slobogin (2011) reviewed the empirical literature on whether requiring law enforcement to obtain a warrant prior to conducting a search improves the probability that a search will return relevant evidence, finding that "the best that can be said, based on the available research...is that if the government really wants particular evidence and the only way to obtain it legally is through a warrant process, it will devote the time and resources necessary to obtain one." Ohm (2009) has argued that under certain circumstances a requirement that law enforcement obtain a warrant may in practice not provide a stronger constraint than a requirement than law enforcement obtain a subpoena, as in certain types of investigations "the police almost always have probable cause whenever they have any suspicion at all." 


\section{PDMP Programs}

\section{A. What are prescription drug monitoring programs?}

State governments have used PDMPs and similar programs to track prescriptions of potentially addictive medication since the 1930s. Early PDMPs relied on triplicate forms to report each filled prescription to state officials via postal mail (Deyo, Irvine et al. 2013), a time-consuming and labor-intensive process that required extensive security for the storage of sensitive records. Early PDMPs were also often limited to collecting information only on Schedule II controlled substances (which have the highest potential for abuse), limiting the scope of information captured by early PDMPs - although an individual state's PDMP may still have included millions of prescription records. ${ }^{1}$

Opioid prescribing began to increase dramatically during the late 1990 s due to a complex and interrelated set of factors: an increased number of patients with chronic pain due to an aging and obese population (Dasgupta, Beletsky et al. 2018), a shift towards incentivizing physicians to treat that pain by using patient satisfaction surveys to gauge physician performance (Sinnenberg, Wanner et al. 2017), and the perception that using opioids to treat pain caused little risk of dependence (Mandell 2016). However, as opioids have a higher potential for dependence than initially recognized, patients who began using opioids pursuant to medical guidance sometimes found the amount of opioids prescribed to be insufficient, and sought additional medication through doctor shopping (requesting overlapping prescriptions from multiple doctors), seeking prescriptions from pill mills (clinics known to provide prescriptions with little justification), and the black market (Perez, Jennings et al. 2017). Use of opioids 
increased both inside and outside the medical context, and opioid dependence, treatment admissions, and associated deaths all skyrocketed.

As policymakers sought a response to the social harms caused by opioid dependence, the number of states with PDMP laws expanded. This expansion was aided by availability of federal funding for state PDMPs (Blumenschein, Fink III et al. 2010). State laws creating PDMPs have varied both across states and over time, as states experimented with different characteristics of the PDMP programs in hopes of more effectively stemming opioid-related harms within their state (Haffajee 2015). Figure 1 below describes changes in state PDMP policies from 2000-2017. As can be seen, the percent of states with operational PDMPs increased steadily during this time period: from slightly more than $30 \%$ in 2000 to $98 \%$ in 2017 . The percent of states with electronic PDMP programs simultaneously increased during this time period, as did the percent of states requiring pharmacists to report prescriptions of Schedule IV and Schedule V controlled substances. 
Figure 1: Changes in State PDMP Policies, 2000-2017²

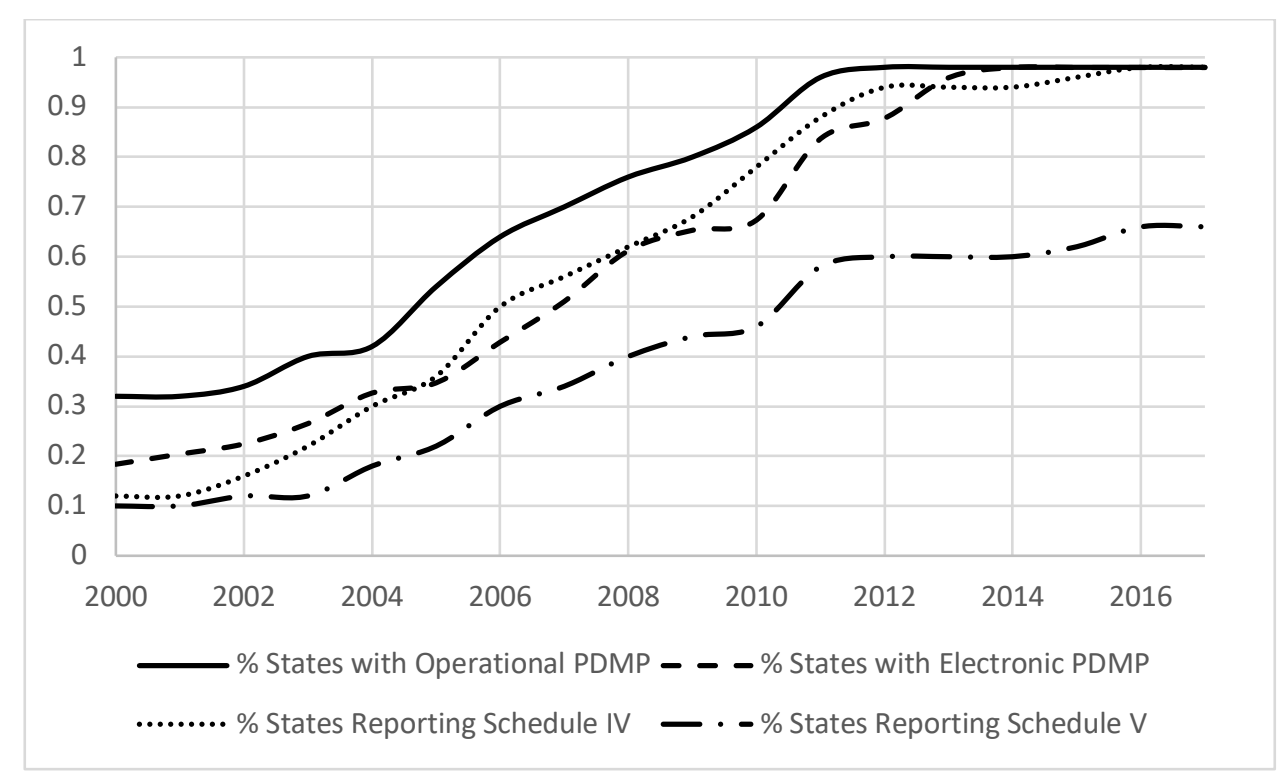

As a result of these changes, the amount of information collected by PDMPs has increased dramatically over the last 20 years. This increase has occurred on both the extensive and intensive margins: the number of states with PDMP programs has expanded and, on average, the data that can be captured by an individual state's PDMP has grown. Due in part to the technical difficulty of collecting and storing information, early PDMPs were usually restricted to collecting information about Schedule II controlled substances, which are thought to have the highest potential for abuse. However, this limitation lead to physicians prescribing unmonitored pain medication in place of the Schedule II controlled substances monitored through PDMPs. For example, "[t]he prominent example in California is the avoidance of schedule II opioids, such as sustained-release morphine, in favor of multiple doses per day of schedule III drugs such 
as Vicodin.” (Fishman 2004) To avoid this substitution effect and ensure that their database captures information about a broader range of potentially risky substances, many PDMPs currently collect information on prescriptions of any medication considered to be a scheduled controlled substance - and some go further to require the reporting of certain medications not considered to be controlled substances (PDMP TTAC 2017). This trend does not appear to be abating. On January 1, 2018, Nebraska began to require reporting of all dispensed prescriptions to their PDMP (Neb. Rev. Stat. § 71-2454(2) (2017)). While recent systematic data are not available for all states, it is likely that hundreds of millions of prescription records are currently captured by state PDMPs nationwide. ${ }^{3}$

Increasing the range of prescription drug information captured by PDMPs also increases the range of sensitive medical conditions implicated by this information. Testosterone, a schedule III drug, is used to treat gender dysphoria; valium, a schedule IV drug, is used to treat anxiety disorders; oxazepam, a schedule IV drug, is used to treat withdrawal from alcohol (Mejia 2014). However, it should not be assumed that PDMP programs that only capture information about schedule II drugs do not implicate sensitive medical conditions. Schedule II drugs include Adderall, which is used to treat attention deficit hyperactivity disorder, and methadone, which is used to treat substance abuse disorder.

As the amount of information collected in PDMPs has grown, so too has the range of intended users of PDMPs. PDMPs are currently designed to be easily accessed by a broad range of professionals involved with prescribing, dispensing, and monitoring 
controlled substances. In contrast to earlier PDMP laws, which used relatively simple technology to collect information on a narrow range of controlled substances, modern PDMPs rely on secure, online databases that allow pharmacists to directly upload information about the prescriptions they fill and allow physicians to download reports on the patients they treat. Pharmacists are required to upload information about their patients soon after they dispense medication, although the window for timely reporting varies from state-to-state (Legal Science 2018). States have also begun to require, rather than allow, physicians to check their patients' PDMP records when prescribing substances monitored by their PMDP (Haffajee, Jena et al. 2015). These databases can also be accessed by other government entities, including medical/pharmacy licensing boards and law enforcement. Furthermore, as patients may see doctors in multiple states, a majority of states currently have provisions in place allowing their PDMP data to be shared with PDMP programs from other states under some circumstances (PDMP TTAC 2017).

By design, modern PDMPs automatically collect an enormous amount of highly sensitive medical information, and provide that information to a variety of government and private actors in the most frictionless way possible. Unsurprisingly, they also raise significant privacy concerns - particularly when PDMP data is accessed by law enforcement officers. As will be discussed in depth in Section III, states use a variety of techniques to regulate law enforcement access to PDMP information. However, there have been several high-profile instances of questionable or unexpected use of PDMP data by law enforcement. After a Utah town realized that morphine was going missing from 
their ambulances in 2013, law enforcement officers obtained PDMP records for every employee of the local fire department - almost 500 in total. An initial review of these records revealed potentially concerning use of opioids by two fire department employees completely unrelated to the missing morphine; charges brought by the Utah Attorney General against both employees were eventually dropped after more than a year of investigation and negotiations (Silver Sweeney 2015). In Tennessee, a police officer was fired after searching the PDMP for information about a drug task force director and three other people without notifying his superior or first generating a case number as required by state law (Brumley v. City of Cleveland, No. E2014-02213-COA-R3-CV (Tenn. Ct. App. Aug. 26, 2015)). In Florida, attorneys for defendants accused of drug trafficking were provided with unredacted PDMP information for over 3,000 individuals, leading some to question the efficacy of protections for PDMP information (Kam 2013, Unger 2014).

\section{B. Evidence of PDMP effectiveness}

Given both the increased reliance on PDMPs as a tool for addressing opioid misuse and the serious concerns about associated privacy risks, there has been significant interest in evaluating whether the public health claims associated with PDMPs are supported by the evidence. As trends in state law have changed key aspects of PDMPs over time, evaluations of PDMPs must be understood in the context of the specific laws in place at the time. Early PDMPs - which collected information on a limited range of controlled substances and required less participation from physicians - were generally 
observed to have some limited effect on opioid prescribing (Reifler, Droz et al. 2012) and opioid use behaviors (Worley 2012), but little to no impact on overdose deaths (Paulozzi, Kilbourne et al. 2011). Subsequent studies that considered the requirements of particular PDMP laws found that laws that placed greater requirements on physicians had an observable impact on overdose deaths (Dowell, Zhang et al. 2016, Pardo 2017). In total, the research suggests that PDMPs have a promising but uncertain effect on opioid-related public health outcomes, leading one scholar to comment that "[t]here is still much we do not understand about what causes these variations in outcomes, nor do we have a good sense of how the PDMPs that appear to reduce OA-related deaths achieve that result." (Davis 2017) Furthermore, even if PDMPs improve opioid related outcomes, they may exacerbate other public health harms as opioid users turn to easier-to-obtain drugs (Fink, Schleimer et al. 2018).

Few studies have considered the role that law enforcement access to PDMP information may play in changing public health or safety outcomes. Law enforcement officers that use PDMP information generally describe it as a helpful tool for investigating inappropriate use of prescription medication (Perez, Jennings et al. 2017). According to law enforcement agencies, "PDMPs are reported useful in facilitating criminal investigations", although it is unclear what evidence supports this conclusion (Paulozzi, Kilbourne et al. 2011). Neither the impact of privacy protections on law enforcement use of PDMP data nor the impact of law enforcement access to PDMP information on either opioid-related criminal investigations or opioid-related health outcomes appear to have been evaluated. 


\section{Laws governing law enforcement access to PDMP data}

\section{A. Federal and State Constitutional Protections for PDMP Information}

Although several high-profile court cases have considered the constitutionality of PDMPs, there is still significant uncertainty about whether the Fourth Amendment governs law enforcement access to PDMP information. The Supreme Court most directly ruled on the constitutionality of PDMPs in Whalen v. Roe, holding that collection of Schedule II prescription information by a State PDMP was not "sufficient to constitute an invasion of any right an invasion of any right or liberty protected by the Fourteenth Amendment." (Whalen v. Roe, 429 U.S. 589, 603 (1977)). However, the Court in Whalen did not rule on the constitutionality of law enforcement access to PDMP information under the Fourth Amendment.

Under the Katz reasonable expectation of privacy test, it may appear that law enforcement access to PDMP information should be considered a search for purposes of the Fourth Amendment. Medical information is generally considered highly sensitive, and courts have previously had "no difficulty concluding that protection of a right to privacy in a person's prescription drug records, which contain intimate facts of a personal nature, is sufficiently similar to other areas already protected within the ambit of privacy." (Douglas v. Dobbs, 419 F.3d 1097, 1102 (10th Cir. 2005). However, prescription drugs - particularly those scheduled under the Controlled Substances Act are highly regulated by multiple government entities, and individuals have a lower expectation of privacy in highly regulated activities (DEA vs. Utah Department of 
Commerce, 16-cv-611-DN-DBP (D. Utah Feb. 16, 2016)). Furthermore, under the third party doctrine, there may be an argument that PDMP data should not be protected as individuals have voluntarily disclosed this information in the course of receiving treatment - although there is also an argument that individuals have a reasonable expectation that disclosures made in a medical environment will not be shared indiscriminately (Ferguson v. City of Charleston, 532 U.S. 67, 79 (2001)).

Several federal courts have considered the issue of whether the Fourth Amendment protects PDMP information; these cases often do not definitively conclude whether Fourth Amendment protections apply. In Pyle v. Woods, the 10th Circuit rejected a Plaintiff's argument that they should be able to recover civil damages after law enforcement obtained their PDMP information without a warrant because, at the time the records were accessed, there was no caselaw assessing the constitutionality of warrantless law enforcement access to PDMP databases (Pyle v. Woods, No. 15-4163, 10-11 (10th Cir. 2017). In Oregon Prescription Drug Monitoring Program v. DEA, the district court held Fourth Amendment protections do apply to PDMP information, as "it is more than reasonable for patients to believe that law enforcement agencies will not have unfettered access to their [prescription] records." (Oregon Prescription Drug Monitoring Program v. DEA, 998 F. Supp. 2d 957, 966 (2014)) Although Ninth Circuit later overturned this holding on standing grounds, they did so while "acknowledg[ing] the particularly private nature of the medical information at issue." (Oregon Prescription Drug Monitoring Program v. DEA, 860 F.3d 1228, 1235 (2017)) However, the Ninth Circuit also held that Oregon's requirement that law enforcement officers obtain a warrant prior to accessing 
PDMP information was preempted by the Controlled Substances Act (CSA), under which the DEA can obtain evidence to investigate narcotics crimes through an administrative subpoena (Oregon Prescription Drug Monitoring Program v. DEA, 860 F.3d 1228 (2017)).

Very few state courts have considered whether law enforcement access to PDMP information violates an individual's rights under either the Fourth Amendment or their state constitution; those that have are split on whether Fourth Amendment protections apply. For example, in State v. Skinner, the Louisiana Supreme Court held that law enforcement could not search prescription records without a warrant (State v. Skinner, 10 So. 3d 1212 (La. 2009), rejecting the argument that "Whalen's upholding of a regulatory scheme for the monitoring of prescriptions for controlled substances diminishes a person's Fourth Amendment privacy interest to permit warrantless governmental intrusion during the course of a criminal investigation." (Skinner v. State, 10 So. 3d at 1218) In contrast, the California Supreme Court recently held that law enforcement did not violate the state's constitutional right to privacy by obtaining PDMP information without either a warrant or subpoena (Lewis v. Superior Court of Los Angeles, 5.Cal.5th 561 (2017)). However, in this case the PDMP records were used as evidence against the physician who prescribed controlled substances - rather than the patients who received them - and the physician forfeited any claims under the Fourth Amendment by failing to raise them at trial. 


\section{B. State Statutory Protections for PDMP Information}

Law enforcement access to PDMP information is primarily governed through statutory law. The majority of PDMP statutes were introduced in quick succession with little opportunity to learn from the effectiveness of PDMP programs in other states, leading some to argue that the "state replication of PDMPs has exemplified disorganized policymaking in the face of a serious public health crisis." (Haffajee 2015) Consequently, the resulting statutes vary widely across many dimensions - including whether and how they allow law enforcement to access PDMP data. In this section, I explore the various mechanisms that states have used to allow and regulate law enforcement access to PDMPs by identifying the key themes and common trends running through these statutes. 
Figure 2: State Policies Regarding Law Enforcement Access to PDMP Data, 2010-2017

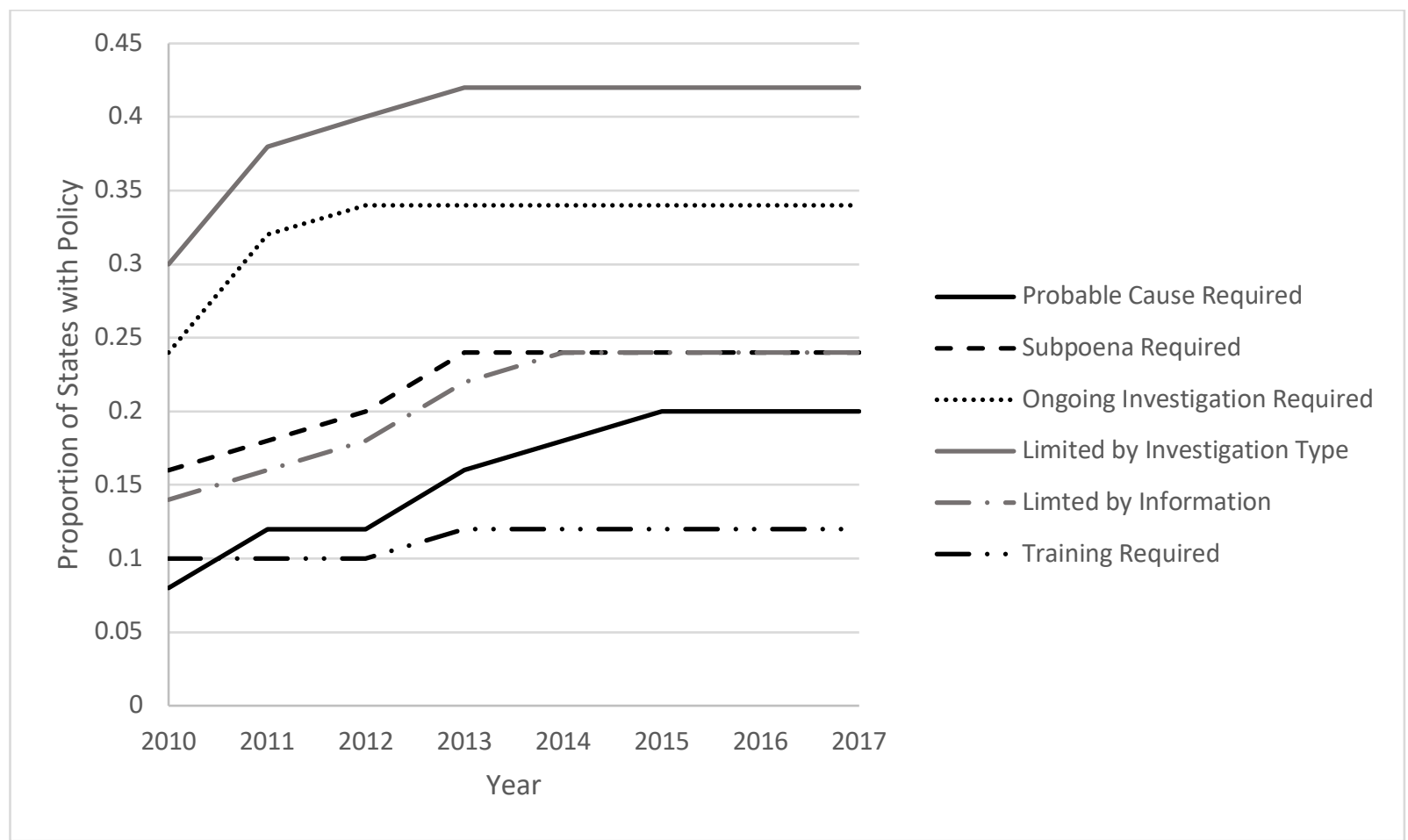

\section{Type of legal showing required}

States vary in the minimum standard law enforcement must meet before they are allowed to access PDMP data, and whether that proof must be presented to and evaluated by an impartial magistrate. Some states require a finding of probable cause by a court before law enforcement may obtain PDMP information. For example, Alaska law provides that "federal, state, and local law enforcement authorities may receive printouts of information contained in the databased under a search warrant, subpoena, or order issued by a court establishing probable cause for the access and use of the information." (Alaska Stat. §17.30.200(d)(5) (2016)) Other states allow law enforcement access to 
PDMP data upon issuance of a subpoena, without explicitly requiring probable cause (CO Rev. Stat. § 12-42.5-404(3)(e) (2016)).

Rather than mandating that law enforcement demonstrate probable cause or obtain a subpoena, other states instead require that law enforcement show that their request is related to an active criminal investigation. For example, Arizona requires that information is provided "only if the requesting agency states in writing that the information is necessary for an open investigation or complaint." (Ariz. Rev. Stat. §362604(D)(4) (2017)) The requirement that law enforcement demonstrate a connection to an existing case is sometimes coupled with the requirement that the investigation be related to an identified person or persons. (Wash. Rev. Code $§ 70.225 .050(3)(d)(2018)$ ) State statutes may also specify how law enforcement officers can demonstrate that their request is related to a criminal investigation, usually by providing the appropriate case number (Ark. Code § 20-7-604(i) (2017); Ohio Admin Code 4729-37-08 (2017)).

Some states do not set forth explicit standards that law enforcement must meet prior to accessing PMDP information. In some cases, the determination of whether law enforcement has demonstrated sufficient cause to obtain PDMP information is left up to the discretion of PDMP officials. For example, Texas law provides that law enforcement and prosecutors "engaged in the administration, investigation, or enforcement" of narcotics laws can obtain PDMP information provided that "the director [of the Department of Public Safety] finds that proper need has been shown." (Texas Health \& Safety Code $\S$ 481.076(a)(3) (2018)) Finally, some state statutes do not specify whether and under what circumstances law enforcement can obtain access to PDMP information. 
For example, Nebraska's PDMP statute specifies that the state PDMP may be accessed by prescribers and dispensers, but makes no mention of law enforcement access (Neb. Rev. Stat. § 71-2454 (2017)).

\section{Access to PDMP based on investigator type or training}

In determining the process by which law enforcement can obtain access to PDMP data, some states differentiate between officers that have either specialized expertise in narcotics investigations or particular training in accessing PDMP materials, and those that do not. Under these legislative schemes, officers with specialized expertise or training are allowed either easier or exclusive access to PDMP information. For example, Illinois allows local law enforcement officers who are "approved by the Department to receive information of the type requested for the purpose of investigations involving controlled substances" to receive PDMP information, although some state investigators can obtain access if they are engaged in a narcotics-related investigation (720 Ill. Comp. Stat. § 570/138(d) (2017)). States may also elect to limit access to PDMP data based on the employer of the officer seeking information. For example, Alaska does not allow PDMP information to be shared with the federal government (Alaska Stat. § 17.30.200(d) (2017)).

\section{Access to PDMP based on investigation type}

In regulating access to PDMP data, some states have elected to differentiate between narcotics-related investigations and non-narcotics-related investigations. 
Generally, these policies are crafted to allow easier or exclusive access to PDMP data during narcotics investigations. For example, Mississippi requires the State Board of Pharmacy to supply "local, state and federal law enforcement officials engaged in the administration, investigation or enforcement of the laws governing illicit drug use" with PDMP data upon request (Miss. Code Ann. § 73-21-127(e) (2017)). Similarly, Florida allows the release of PDMP information to "[a] law enforcement agencies during active investigations of potential criminal activity, fraud, or theft regarding prescribed controlled substances.” (Fla. Stat. § 893.055(7)(c) (2016))

\section{Limiting information received from PDMPS}

Even after an officer has met the requirements to access PDMP information, state statutes may limit the amount of information they can receive. Delaware and Wisconsin require law enforcement to be granted access to the minimum amount of information necessary to fulfill the officer's request; Delaware further requires that identifying information only be provided if nonidentifying information is insufficient (Wisc. Admin. Code CSB §44.11(10) (2017); Del. Code Ann. tit. $16 \S 4798(2)(d)(2017))$. Other states require a clear linkage between the case under investigation and the information requested. For example, West Virginia requires law enforcement officers to tailor their information requests to be "related to a specific patient or a specific individual or entity under investigation.” (W. Va. Code R. §60A-9-5(a) (2017)). The District of Columbia’s PDMP regulations go slightly further, requiring identification of both an individual 
patient, prescriber, or dispenser about whom information is sought, and the time period to be covered (D.C. Mun. Regs. tit. 17, § 10307.4 (2017)).

In addition to limiting the information that law enforcement can receive from PDMPs, states could elect to provide additional protection to certain types of information contained within PDMPs. For example, Pennsylvania has elected to allow law enforcement officers access to PDMP information related to Schedule II controlled substances without a court order, but require a court order prior to releasing information about other controlled substances (35 Pa. Stat. § 872.9(b) (2017)). As Schedule II controlled substances pose higher risk of abuse than other scheduled drugs, allowing law enforcement easier access to information about Schedule II controlled substances suggests an effort to manage tradeoffs between privacy and public health: additional privacy protections are provided where there is less of a public interest in allowing law enforcement easy access to PDMP information.

\section{Proactive reporting based on PDMP information}

While most states have mechanisms that allow law enforcement officers to request access to PDMP information, a much smaller number of states allow or require PDMP officials to bring information to the attention of law enforcement officials under

certain circumstances. New York PMDP officials may provide law enforcement agencies with "relevant information about the suspected criminal activity, including controlled substances prescribed or dispensed" when they have reason to believe that criminal diversion of prescription medications is occurring (New York Pub. Health Law $\S$ 
80.107(k) (2017)). Similarly, Nevada PDMP officials may facilitate information exchange between government officials in order to reduce illegal use of controlled substances (Nev. Rev. Stat. § 453.141(a) (2017)).

\section{Transparency and reporting of law enforcement access to PDMP information}

In addition to prospectively regulating how law enforcement can access PDMP information, some states have created mechanisms to provide retroactive oversight of law enforcement use of PDMP information through reporting, recordkeeping, or other transparency mechanisms. In some instances, these mechanisms place a reporting onus on the law enforcement officers who access PDMP information. For example, Arkansas requires law enforcement agencies that access PDMP information to provide yearly reports accounting for the information accessed by the agency, connecting the information accessed to particular investigations, and describing the status of those investigations (Ark. Code § 20-7-604(j)(1) (2017)).

Other PDMP oversight mechanisms require the PDMP to report law enforcement requests to another agency. In Tennessee, the Board of Pharmacy is required to report law enforcement requests for PDMP information to the district attorney generals and the director of the Tennessee Bureau of Investigation on a bi-yearly basis (Tenn. Code Ann. $\S 53-10-306(j)$ (2012)). The officials receiving this information must confirm that the requests correspond to investigations, and "if the information requested was not relevant or pertinent...investigate the discrepancy and report back.” (Tenn. Code Ann. § 53-10306(j) (2012)) 


\section{Relationship between legal protections and law enforcement use of PDMP data}

The previously described variation in regulation of law enforcement access to PDMP data presents an opportunity for studying how various privacy protections shape law enforcement behavior. In this section, I explore this issue by addressing two questions. First, does law enforcement use of PDMP data vary across states with various levels the legal protections for that data? Second, based on evidence from Utah, do the observed differences before and after the imposition of a warrant requirement vary based on agency or locality characteristics?

\section{A. Data and Methods}

\section{State-level analysis}

To support this analysis, I conducted an exhaustive search for information related to law enforcement use of PDMP data. I obtained data from three sources: administrative reports detailing the number of yearly requests for PDMP data, data on law enforcement requests obtained through requests and interviews with PDMP officials, and information published by investigative reporters who conducted a comprehensive review of law enforcement use of PDMP programs (Greenblatt and Hill 2016). Although some states provided more detailed information for some time periods, all data were aggregated up to the state-year level in order to provide consistent metrics across jurisdiction and time. 
When I could only obtain data describing the number of law enforcement requests for PDMP data in a state for part of a year, I used the available data to estimate the yearly number of requests if at least three months of data were available. By combining information from all these sources, I was ultimately able to obtain 169 observations covering the time period 2010-2017. Figure 3 below depicts the number of states with data available per year.

Figure 3: Data Coverage, by Year

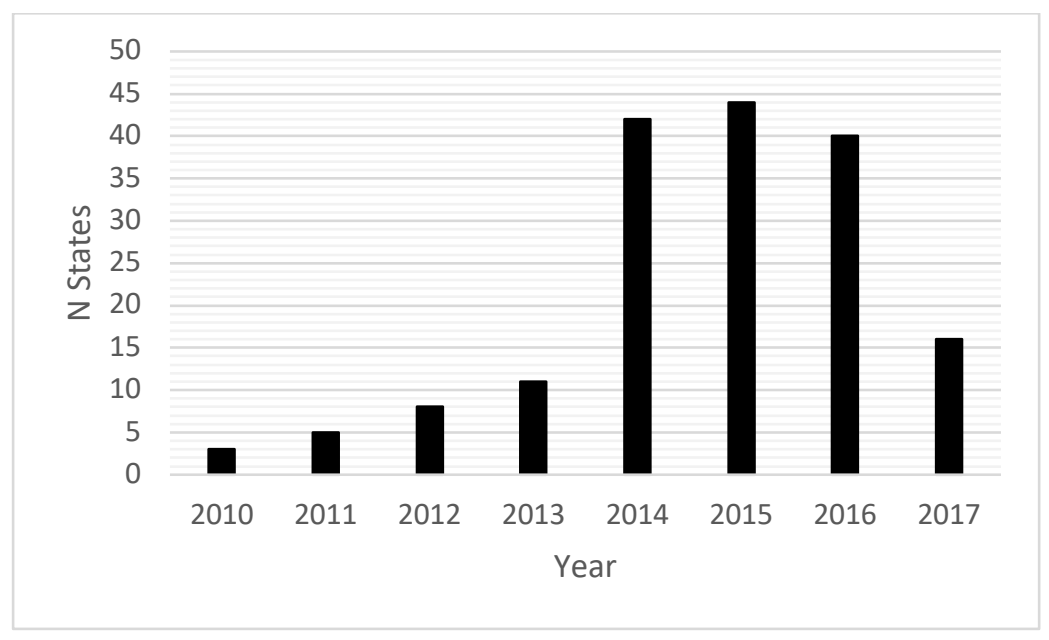

Yearly counts of the number of law enforcement requests for PDMP information were then used to calculate the rate of requests per 100,000 people, as summarized in Table 1 below. 
Table 1: Summary statistics, tabulated for type of restriction on Law Enforcement Access

\begin{tabular}{|c|c|c|}
\hline & & $\begin{array}{c}\text { Law Enforcement PDMP } \\
\text { Request Rate }\end{array}$ \\
\hline Overall & & $\begin{array}{c}70.48 \\
(113.21)\end{array}$ \\
\hline Showing Required & $\begin{array}{c}\text { Probable Cause } \\
\text { Subpoena } \\
\text { Ongoing Investigation } \\
\text { No Requirement }\end{array}$ & $\begin{array}{c}8.74 \\
(10.91) \\
48.50 \\
(57.84) \\
72.33 \\
(85.23) \\
141.45 \\
(116.80)\end{array}$ \\
\hline $\begin{array}{l}\text { Limited by } \\
\text { Investigation Type }\end{array}$ & $\begin{array}{l}\text { Yes } \\
\text { No }\end{array}$ & $\begin{array}{c}83.77 \\
(142.58) \\
59.88 \\
(81.98)\end{array}$ \\
\hline Limited Information & $\begin{array}{l}\text { Yes } \\
\text { No }\end{array}$ & $\begin{array}{c}74.09 \\
(95.10) \\
69.01 \\
(120.16)\end{array}$ \\
\hline Training Required & $\begin{array}{l}\text { Yes } \\
\text { No }\end{array}$ & $\begin{array}{c}176.67 \\
(137.13) \\
53.75 \\
(99.63)\end{array}$ \\
\hline & $\begin{array}{l}\text { Years } \\
\mathrm{N}\end{array}$ & $\begin{array}{c}2010-2017 \\
169\end{array}$ \\
\hline
\end{tabular}

Data on state laws regarding law enforcement use of PDMP data were obtained by a careful review of relevant state statutes, and have previously been described in 
Figure 2. For purposes of this analysis, I focused on those aspects of state statutes that had been adopted in enough states to support analysis. To the greatest extent possible, these data were then checked against the Prescription Drug Abuse Policy System's (PDAPS's) data describing law enforcement access to PDMP data (Legal Science 2018).

A robust set of control variables were used to account for other state characteristics that could impact law enforcement use of PDMP data. Yearly data on state-level opioid prescription rates from the Centers for Disease Control (CDC) (Centers for Disease Control 2017) and opioid-related death rates were obtained from the CDC Wide-ranging OnLine Data for Epidemiologic Research (WONDER) multiple cause of death database (Centers for Disease Control 2018); data on heroin/cocaine possession and sales arrests were obtained from the Federal Bureau of Investigation's Uniform Crime Reports (Kaplan 2018). ${ }^{4}$ Data on a suite of opioid-related state policies were obtained from the Prescription Drug Abuse Policy System, timing of state adoption of Medicaid expansion was obtained from Meinhofer and Witman (2018) and the Commonwealth Fund (2018). State demographic data were obtained from bridged-race population estimates produced by the U.S. Census Bureau and the National Center for Health Statistics, as released through the CDC WONDER database (Centers for Disease Control 2018). Data on penalties for marijuana possession and citizen ideology were obtained through the Correlates of State Policy Project, and economic control data were obtained from the U.S. Census Bureau's Small Area Income and Poverty Estimates Program and the Bureau of Labor Statistics. Summary statistics for control variables can be found in Table 2 below. 
Table 2: Control variables

\begin{tabular}{|c|c|c|c|c|c|}
\hline Category & Control & Overall & $\begin{array}{c}\text { Probable } \\
\text { Cause } \\
\text { Required }\end{array}$ & $\begin{array}{c}\text { Subpoena } \\
\text { Required }\end{array}$ & $\begin{array}{c}\text { Ongoing } \\
\text { Investigation } \\
\text { Required }\end{array}$ \\
\hline \multirow{8}{*}{ Opioid Use Controls } & \multirow{2}{*}{ opioid prescription rate } & 77.09 & 73.64 & 75.78 & 78.99 \\
\hline & & $(21.85)$ & (18.79) & $(17.03)$ & $(25.66)$ \\
\hline & \multirow{2}{*}{ opioid death rate } & 12.06 & 11.24 & 13.50 & 11.34 \\
\hline & & $(7.71)$ & (7.63) & $(8.08)$ & (6.37) \\
\hline & \multirow{2}{*}{$\begin{array}{l}\text { heroin/cocaine possession } \\
\text { arrest rate }\end{array}$} & 53.47 & 39.71 & 70.13 & 47.28 \\
\hline & & (44.14) & (26.16) & $(48.87)$ & (37.37) \\
\hline & \multirow{2}{*}{ heroin/cocaine sales arrest rate } & 22.91 & 12.60 & 29.22 & 24.39 \\
\hline & & $(22.60)$ & (10.54) & $(26.04)$ & $(26.15)$ \\
\hline \multirow{14}{*}{$\begin{array}{l}\text { Opioid-Related } \\
\text { Policies }\end{array}$} & \multirow{2}{*}{$\begin{array}{c}\text { physicians required to access } \\
\text { PDMP }\end{array}$} & 0.21 & 0.05 & 0.19 & 0.24 \\
\hline & & $(0.41)$ & $(0.22)$ & $(0.40)$ & $(0.43)$ \\
\hline & \multirow{2}{*}{$\begin{array}{c}\text { PDMP includes schedule III, IV, } \\
\qquad\end{array}$} & 0.86 & 0.82 & 0.94 & 0.93 \\
\hline & & $(0.33)$ & $(0.38)$ & $(0.23)$ & $(0.24)$ \\
\hline & \multirow{2}{*}{ pain management clinic laws } & 0.23 & 0 & 0.33 & 0.33 \\
\hline & & $(0.42)$ & (0) & $(0.47)$ & $(0.47)$ \\
\hline & \multirow{2}{*}{ naloxone access laws } & 0.60 & 0.56 & 0.58 & 0.54 \\
\hline & & (0.49) & $(0.50)$ & $(0.50)$ & $(0.50)$ \\
\hline & \multirow{2}{*}{ Good Samaritan laws } & 0.48 & 0.48 & 0.50 & 0.41 \\
\hline & & $(0.50)$ & $(0.50)$ & $(0.50)$ & $(0.49)$ \\
\hline & \multirow{2}{*}{ Medicaid expansion } & 0.51 & 0.61 & 0.58 & 0.41 \\
\hline & & $(0.50)$ & $(0.49)$ & $(0.50)$ & $(0.49)$ \\
\hline & \multirow{2}{*}{$\begin{array}{c}\text { medical marijuana dispensaries } \\
\text { allowed }\end{array}$} & 0.27 & 0.28 & 0.33 & 0.22 \\
\hline & & $(0.44)$ & $(0.45)$ & $(0.47)$ & $(0.42)$ \\
\hline \multirow{8}{*}{$\begin{array}{l}\text { Demographic } \\
\text { Characteristics }\end{array}$} & \multirow{2}{*}{ Proportion urban population } & 0.73 & 0.71 & 0.72 & 0.74 \\
\hline & & $(0.13)$ & $(0.14)$ & $(0.13)$ & $(0.12)$ \\
\hline & \multirow{2}{*}{ Proportion white } & 0.72 & 0.79 & 0.71 & 0.69 \\
\hline & & $(0.15)$ & $(0.08)$ & $(0.13)$ & $(0.17)$ \\
\hline & \multirow{2}{*}{ Proportion Black } & 0.09 & 0.05 & 0.13 & 0.09 \\
\hline & & $(0.08)$ & $(0.04$ & $(0.09)$ & $(0.07)$ \\
\hline & \multirow{2}{*}{ Proportion Hispanic } & 0.10 & 0.08 & 0.09 & 0.13 \\
\hline & & $(0.10)$ & $(0.03)$ & $(0.07)$ & $(0.12)$ \\
\hline
\end{tabular}




\begin{tabular}{|c|c|c|c|c|c|}
\hline & Proportion female & $\begin{array}{c}0.50 \\
(0.008)\end{array}$ & $\begin{array}{c}0.50 \\
(0.01)\end{array}$ & $\begin{array}{c}0.50 \\
(0.006)\end{array}$ & $\begin{array}{c}0.50 \\
(0.008)\end{array}$ \\
\hline & Proportion aged 20-29 & $\begin{array}{c}0.13 \\
(0.008)\end{array}$ & $\begin{array}{c}0.14 \\
(0.01)\end{array}$ & $\begin{array}{c}0.13 \\
(0.005)\end{array}$ & $\begin{array}{c}0.14 \\
(0.008)\end{array}$ \\
\hline & Proportion aged 30-39 & $\begin{array}{c}0.12 \\
(0.007)\end{array}$ & $\begin{array}{c}0.13 \\
(0.009)\end{array}$ & $\begin{array}{c}0.12 \\
(0.007)\end{array}$ & $\begin{array}{c}0.12 \\
(0.005)\end{array}$ \\
\hline & Proportion aged 40-49 & $\begin{array}{c}0.12 \\
(0.008)\end{array}$ & $\begin{array}{c}0.12 \\
(0.006)\end{array}$ & $\begin{array}{c}0.12 \\
(0.009)\end{array}$ & $\begin{array}{c}0.12 \\
(0.009)\end{array}$ \\
\hline & Proportion aged 50-59 & $\begin{array}{c}0.20 \\
(0.006) \\
\end{array}$ & $\begin{array}{c}0.20 \\
(0.009) \\
\end{array}$ & $\begin{array}{c}0.20 \\
(0.004)\end{array}$ & $\begin{array}{c}0.20 \\
(0.004) \\
\end{array}$ \\
\hline \multirow{3}{*}{$\begin{array}{c}\text { Economic } \\
\text { Characteristics }\end{array}$} & Unemployment rate & $\begin{array}{c}5.35 \\
(1.59)\end{array}$ & $\begin{array}{c}5.28 \\
(1.68)\end{array}$ & $\begin{array}{c}5.79 \\
(1.64)\end{array}$ & $\begin{array}{c}5.24 \\
(1.65)\end{array}$ \\
\hline & Poverty rate & $\begin{array}{l}13.96 \\
(3.07)\end{array}$ & $\begin{array}{l}12.65 \\
(2.87)\end{array}$ & $\begin{array}{l}13.81 \\
(2.80)\end{array}$ & $\begin{array}{l}14.72 \\
(2.96)\end{array}$ \\
\hline & Median income (in thousands) & $\begin{array}{l}56.05 \\
(9.75)\end{array}$ & $\begin{array}{l}58.59 \\
(9.42)\end{array}$ & $\begin{array}{c}57.00 \\
(11.14)\end{array}$ & $\begin{array}{l}54.18 \\
(8.88)\end{array}$ \\
\hline
\end{tabular}

These data were then analyzed using a Poisson regression to estimate the relationship between the rate of law enforcement requests for PDMP data and a set of variables describing the available legal protections for PDMP data. The specific model used is described in equation 1 below, where $P$ denotes a vector of policy variables and $X$ denotes a vector of control variables, including year fixed effects. Standard errors were clustered on the state level.

$$
\ln (P D M P \text { request rate })=\alpha+\beta P+\gamma X
$$

\section{Sub-State Analysis}


While this analysis allows exploration of the impact of law enforcement access to PDMP data on the state level, it may also obscure important sub-state variation. To address this concern, I explored how different agencies in Utah responded to the passage of SB 119, a statute changing the requirements for accessing Utah's PDMP by mandating that law enforcement obtain a warrant prior to accessing PDMP data. The Utah Office of the Legislative Auditor General was commissioned to report on law enforcement use of the CSD both immediately before and after Utah passed SB 119 (Office of the Legislative Auditor General 2015). As part of this report, the Legislative Auditor General released a list of the number of times law enforcement sought information from the CSD for an 18month period surrounding the passage of SB 119, delineated by the agency requesting the information. While this information is only available over a very limited time period, ${ }^{5}$ it can be used to explore how requiring a warrant to obtain PDMP information may have had a differential impact on different types of agencies.

\section{B. Relationship between law enforcement use of PDMP data and applicable} legal protections

As summarized in Table 3 below, there appears to be a correlation between the standard of proof that law enforcement must meet prior to accessing PDMP data and the rate at which law enforcement requests use of these data. Moreover, the magnitude of this correlation falls into an expected pattern when the impact of various standard of proof policies are considered: more burdensome requirements have a greater impact on 
law enforcement use of PDMP data. State policies requiring law enforcement demonstrate probable cause prior to obtaining PDMP data had the greatest impact on PDMP usage. If all other factors are held constant, the log of the PDMP request rate is 2.90 requests per 100,000 people lower in states that require probable cause for obtaining PDMP information than in states that place no requirements on law enforcement requests for PDMP information - corresponding to a PDMP usage rate in states that require probable cause that that is about $5 \%$ of the usage rate for states that do not require probable cause.

A similar phenomenon can be seen when law enforcement is required to obtain a subpoena prior to requesting PDMP information and when law enforcement is required to demonstrate a connection to an ongoing investigation prior to requesting PDMP information, although the apparent effect size is smaller. All else held constant, states that require law enforcement to obtain a subpoena prior to requesting PDMP information are expected to have a PDMP request rate that is about $28.4 \%$ of the PDMP request rate in states that place no requirements on law enforcement requests for PDMP information. Similarly, all else held constant, states that require law enforcement to demonstrate a connection to an existing case are expected to have a PDMP request rate that is about $32.1 \%$ of the PDMP request rates in states that place no requirements on law enforcement requests for PDMP information 
Table 3: Relationship between regulation of law enforcement access to PDMPS and law enforcement use of PDMPS

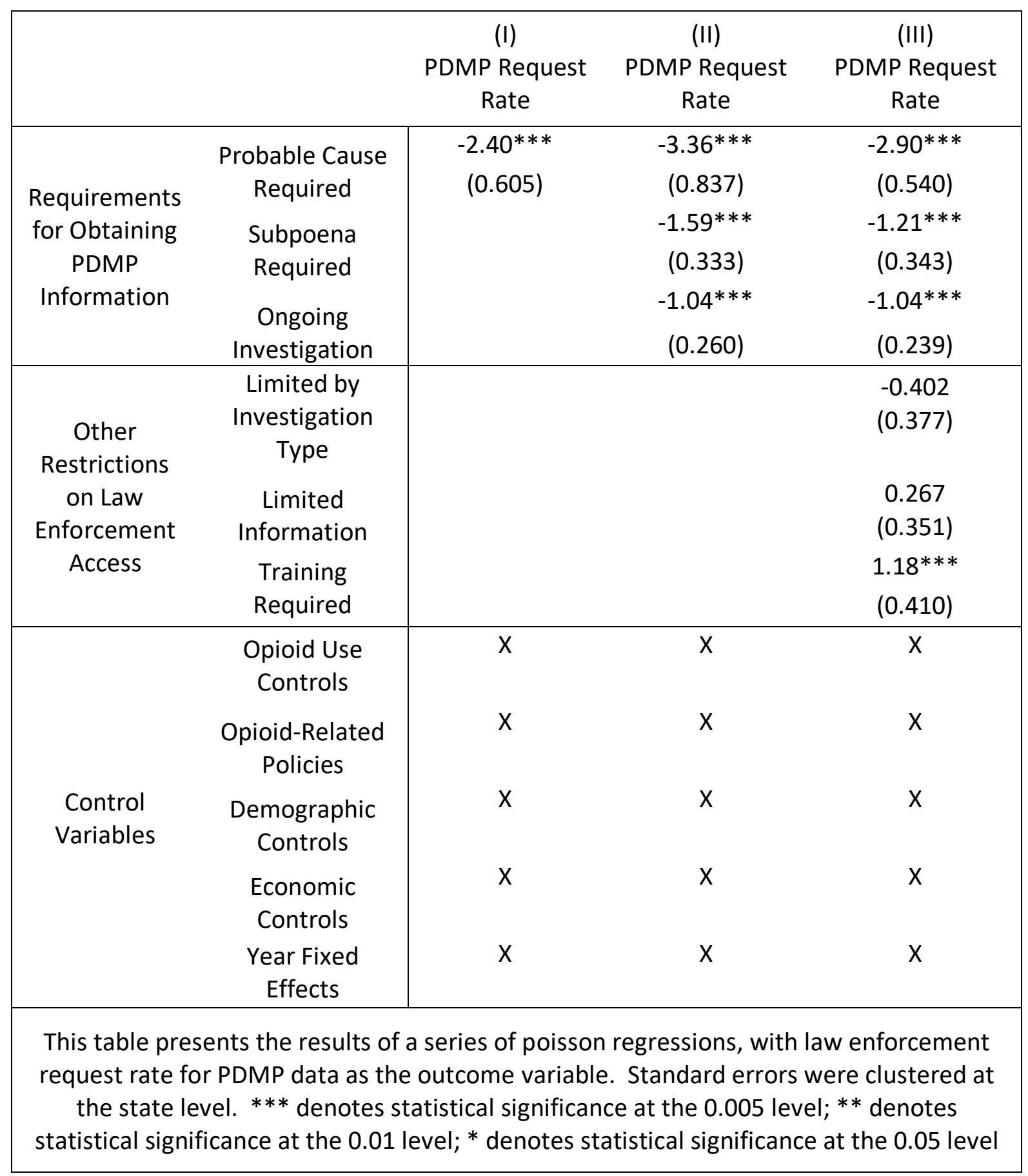


However, other mechanisms for regulating law enforcement access to PDMP data did not appear to be correlated with a reduction in law enforcement use of PDMP data. No statistically significant relationship was observed between the rate of law enforcement PDMP requests and state policies limiting PDMP access by investigation type or limiting the information that can be obtained from PDMPs. Interestingly, requiring law enforcement to undergo training prior to obtaining PDMP information appears to be correlated with an increase in PDMP usage. This finding suggests that law enforcement officers who receive PDMP training may increase their use of PDMP information, either because the training program teaches them new ways to use PDMP information or because law enforcement officers feel the need to request more PDMP information to justify the time spent undergoing the training program.

I tested the robustness of these results in several ways. First, I recalculated my results after dropping any imputed data. The results of this analysis were virtually identical to my main results: coefficients were similar but slightly larger in magnitude and similar in terms of statistical significance. Second, to ensure that my results were not being driven by data from any particular state or year, I dropped each state-year pair one at a time and recalculated my results. My results were largely identical each time. Figure 4 below shows how the coefficient describing the relationship between the PDMP request rate and the probable cause requirement changed during this process. As can be seen, the observed relationship between the PDMP request rate and probable cause requirement was largely unchanged by systematic deletion of state-year pairs: in all but 3 cases, the 
coefficient on the probable cause requirement variable remained in a range between -2.8 and -3.1 .

Figure 4: Sensitivity of the coefficient of the

probable cause requirement variable to deletion of state-year pairs

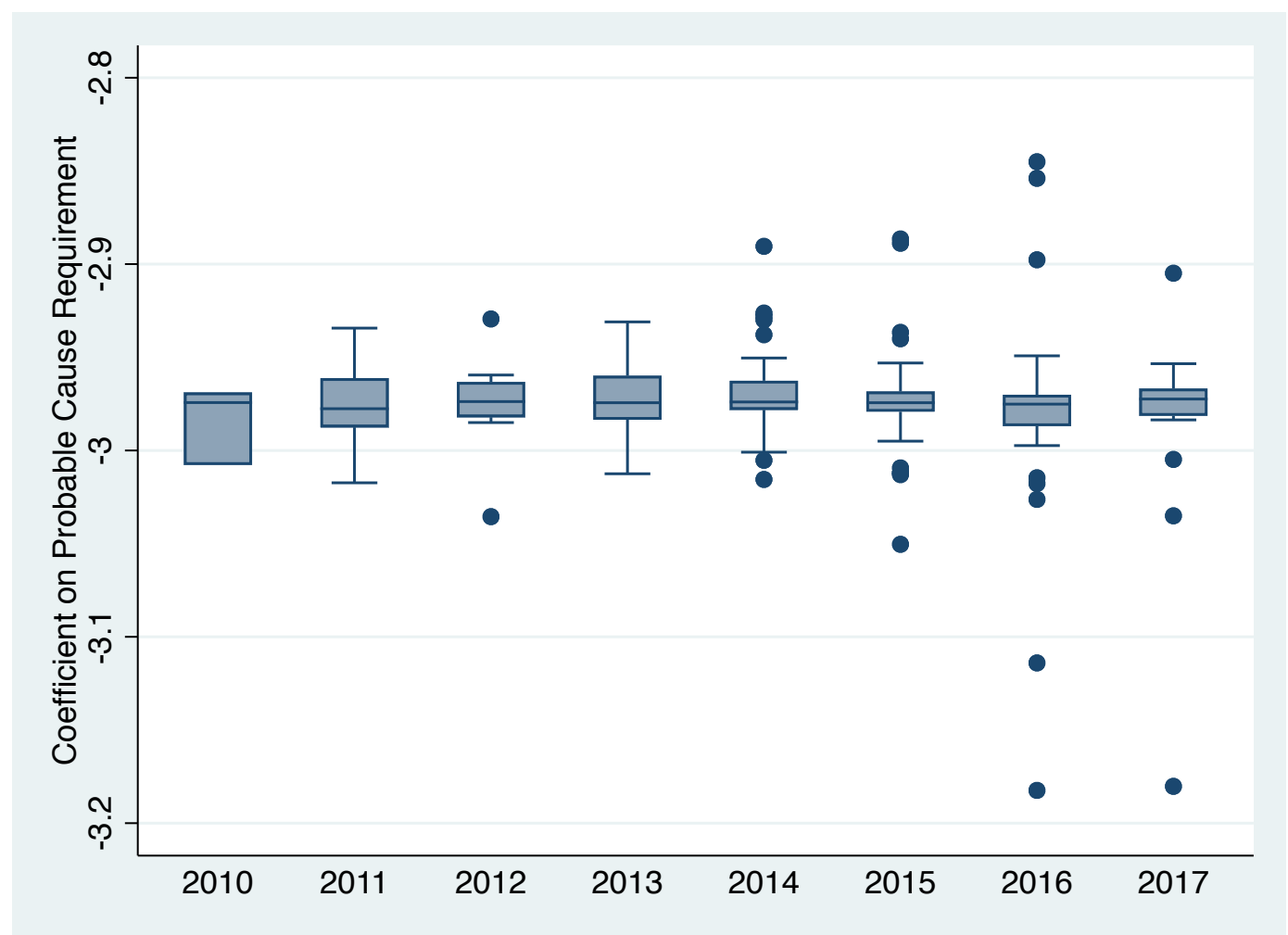

On the whole, this analysis suggests that requiring law enforcement to meet a specified standard of proof prior to obtaining PDMP information is associated with fewer law enforcement requests for PDMP information. No negative relationship is observed between the PDMP request rate and other mechanisms for regulating law enforcement access (such as limiting use of PDMP data to narcotics related cases). However, requiring law enforcement to undergo training appears to be associated with an increase in law enforcement use of PDMP information. 
However, there are several significant limitations. First, this analysis only demonstrates a correlation between policies regulating law enforcement access to PDMP information and law enforcement use of that information, and cannot be used to support causal inference. Additionally, as the available data only describe the rate of law enforcement requests for PDMP information, policies regulating law enforcement access could change investigations that use PDMP information in a variety of important ways that cannot be observed from these data. For example, even if limiting the information that law enforcement can obtain from PDMP databases does not affect the frequency with which law enforcement requests this information, it may nevertheless make investigations that use PDMP information more expensive than they would be if unrestricted PDMP information was provided. Consequently, this analysis does not suggest that requiring law enforcement to meet a specified standard of proof prior to obtaining PDMP information is the only form of regulation that has any impact on law enforcement investigations that use PDMP information. Finally, as this analysis utilizes state-year data, it may obscure variation in the effects of regulating law enforcement access to PDMP information across different localities or different types of agencies. This limitation is partially addressed in the next section, using evidence from a policy change in Utah.

C. Substate variation in the relationship between law enforcement use of PDMP data and applicable legal protections: Evidence from Utah 
Utah's PDMP - commonly referred to as the Utah Controlled Substances Database (CSD) program - initially became operational in 1996 (PDMP TTAC 2018). At the time the CSD was created, the contents of the database were easily accessible to law enforcement. Under the 2014 version of Utah Code, CSD information was available to "federal, state, and local law enforcement authorities, and state and local prosecutors, engaged as a specific duty of their employment in enforcing laws" related to controlled substances or Medicaid abuse (Utah Code § 37f-3-301 (2014)). However, several highprofile incidents of expansive use of CSD information by law enforcement raised significant concerns about whether these data should be provided with additional privacy protections (Schwartzapfel 2017). As the Utah Office of the Legislative Auditor General later described, while "an associate attorney general stated that law enforcement did not illegally access the CSD ...in one case, the way that information was used was illegal and in the other case, though not illegal, the way it was used caused great hardship for one individual." (Office of the Legislative Auditor General 2015)

Consequently, the Utah Legislature passed SB 119 in 2015. Under this statute, law enforcement was required to obtain a search warrant prior to accessing identifiable information contained within the CSD (Utah SB 119 (2015)). Data released in a report by the Utah Office of the Legislative Auditor General demonstrate that the passage of SB 119 was followed by a large and sustained reduction in the number of law enforcement requests for information from Utah's CSD (Office of the Legislative Auditor General 2015). As can be seen by figure 5 below, the law enforcement PDMP request rate dropped from over 280 yearly requests/100,000 people to approximately 10 yearly 
requests/100,000 people. This change appears to be unique to Utah; a comparison group constructed from all other states with available data over this time period appears relatively stable. ${ }^{6}$

Figure 5: Law enforcement requests for PDMP information, before and after the passage of Utah SB 119

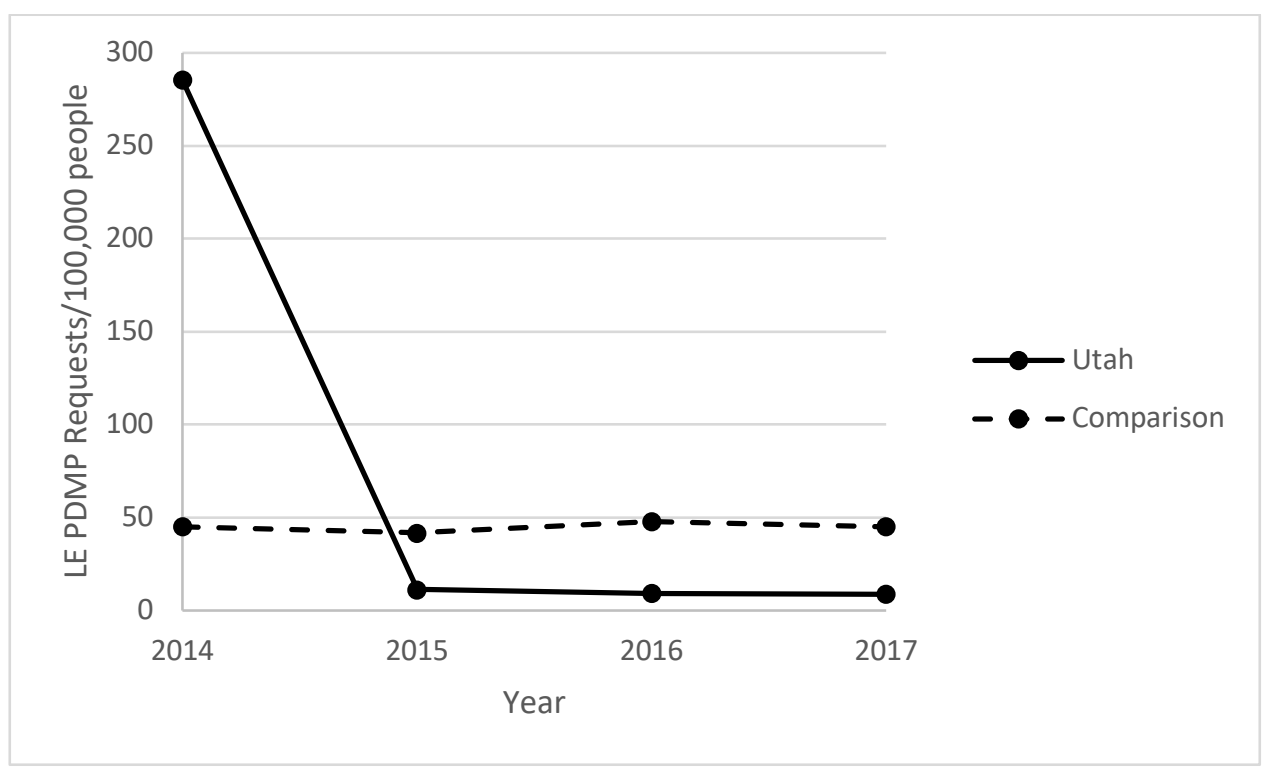

After the passage of SB 119, most agencies reduced their number of requests for CSD information dramatically. The observed percent difference ${ }^{7}$ is similar for federal, state, and local agencies: there was a $100 \%$ reduction in the number of requests made by federal agencies, a $99 \%$ reduction in the number of requests made by state agencies, and a $94 \%$ reduction in the number of requests made by local agencies. However, as can be seen in Figure 6 below, variation in the percent difference of the number of requests can be observed if agencies are categorized based on their primary function. While a percent difference of greater than $95 \%$ can be observed for probation agencies, investigative 
agencies, and district attorney's offices, the observed percent difference is slightly less than $50 \%$ for agencies that focus on investigating and enforcing narcotics crimes. In other words, it appears that requiring a warrant prior to obtaining information from Utah's CSD is associated with a smaller reduction in the number of requests made by narcotics agencies compared with other type of agencies.

Figure 6: Percent Reduction in CSD Requests, by Agency Type

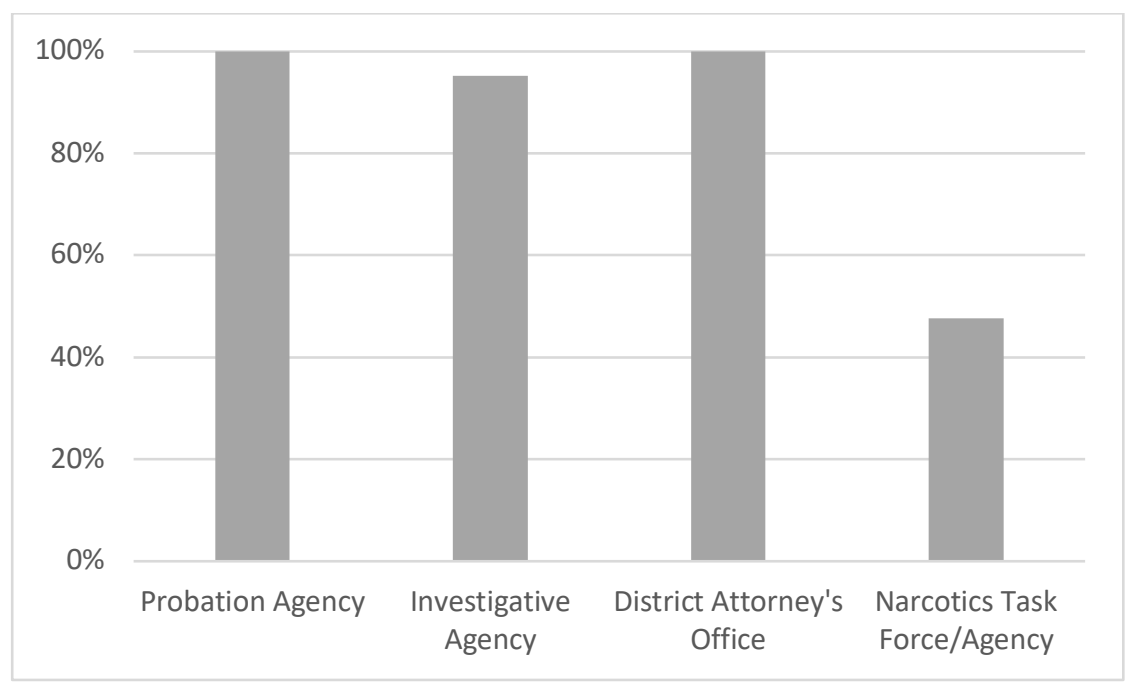

To explore whether geographic differences in the impact of requiring a warrant on requests for CSD information can be observed, requests made by local agencies were aggregated to the county level, ${ }^{8}$ and the percent difference of the number of requests made before and after SB 119 was calculated for each county. Figure 7 below a countylevel map of Utah, with counties shaded in darker colors if there was a greater observed percent difference in the number of CSD requests made, and lighter colors if there was a smaller observed percent difference. ${ }^{9}$ 


\section{Figure 7: Geographic Distribution of Percent Reduction in CSD Request in Utah}

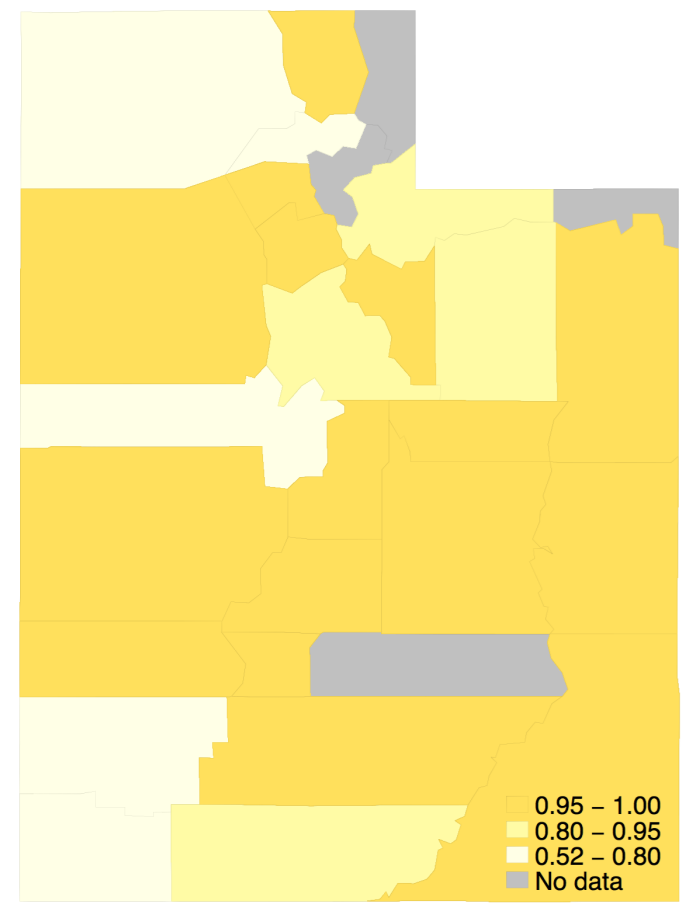

No trends are apparent from this analysis. The three most populous counties in Utah - Salt Lake County, Utah County, and Davis County - all showed a similarly high percent difference in the number of CSD requests made before and after SB 119. On the other hand, the next most populous county - Weber County - was least affected by the passage of SB 119. The smallest counties for which data are available - Piute County, Garfield County, and Kane County - all also appear to have a high percent difference in CSD requests. Consequently, the size of the county does not appear to be related to the observed change in the number of CSD requests after SB 119. However, more data are needed in order to understand why there does not appear to be a relationship between the size of a locality and the impact of requiring a warrant to obtain CSD information. It could be that the size of the locality does not affect whether requiring a warrant to obtain 
information changes law enforcement behavior - but the size of the locality could also have an impact on law enforcement behavior that is not observable from relatively few observations over a short period of time.

While the information provided by the Legislative Auditor General's report allows for suggestive exploratory analyses, the robustness of these analyses should not be overstated. These data represent the experience of one state over a very short period of time, and may not be indicative of how agencies in other states would respond or what variation might be apparent over a longer period of time. Additionally, given that the policies governing access to Utah's CSD have changed since 2015, the differences between CSD usage by different agencies may have also changed since release of the Legislative Auditor General's report. In particular, after the Utah District Court ruled that the Controlled Substances Act preempts Utah's requirement that law enforcement obtain a warrant prior to accessing information from the CSA (DEA vs. Utah Department of Commerce, 16-cv-611-DN-DBP (D. Utah Feb. 16, 2016)), the state agreed to release information to the DEA without a warrant in August 2017 (Whitehurst 2017). Allowing federal law enforcement officers to access PDMP data more easily than state law enforcement officers may create incentives for cooperation between state and federal agents, and may therefore change the frequency with which state officials request PDMP information. 


\section{Discussion and Conclusions}

On the whole, these findings both support and complicate the standard assumption that law enforcement efforts to obtain information can be changed by increasing the costs - legal or otherwise - of seeking information. In the context of PDMP data, law enforcement information requests are substantially less frequent when costs are imposed by requiring law enforcement to first demonstrate probable cause or obtain a subpoena. However, imposing costs on law enforcement information collection may not have a uniform impact on all types of agencies, and not all types of costs are associated with an observable change in law enforcement behavior. In this section, I discuss each of these points in depth.

First, law enforcement use of PDMP information is highly sensitive to presence of certain costs associated with obtaining that information, conforming with the theory that law enforcement officers act as rational actors when seeking information. In states where law enforcement can access PDMP information on request, the costs of obtaining this information is negligible: law enforcement officers are required to fill out a short form or make a request through an online portal, and they can expect these requests will generally be approved within minutes or hours. Consequently, as observed in my analysis, a rational law enforcement officer would frequently be willing to seek PDMP information, even where they only expect it to have minimal benefit in a particular investigation.

In states where law enforcement is required to demonstrate probable cause or obtain a subpoena prior to obtaining PDMP information, the costs of obtaining this information are high in comparison, due to both the added evidentiary requirement and 
administrative burden. Correspondingly, law enforcement would have to foresee a greater expected benefit before they would be willing to seek PDMP information, and we would expect rational law enforcement officers to seek PDMP information less often. According to prior research, law enforcement officers who use PDMPs do describe the information they obtain as useful for identifying instances of doctor shopping, with one officer explaining that prescription records " "tell a story which cannot be denied especially after follow-up with the Doctors and Pharmacies.'” (Perez, Jennings et al. 2017) These benefits may justify the costs required to obtain PDMP information under some circumstances.

However, even if increased standards for obtaining PDMP data are associated with lower law enforcement use of that data, it does not necessarily follow that the difference is always meaningful from a policy perspective. Although a requirement that law enforcement obtain a subpoena is theoretically and doctrinally distinct from a requirement that law enforcement demonstrate their request is related to an ongoing investigation, the frequency of PDMP use associated with both policies is substantially similar in magnitude. This may suggest that a subpoena requirement imposes few additional costs on law enforcement compared with a requirement that law enforcement demonstrate that their request is related to an ongoing investigation.

Second, preliminary evidence suggests that, under some circumstances, certain types of agencies are more sensitive to changes in cost than others. After the passage of SB 119, narcotics-oriented agencies in Utah were observed to have a smaller reduction in their PDMP request rate than other types of agencies. Although the exact mechanism 
may be unclear, this finding suggests that that the specialized expertise concentrated in narcotics agencies may partially insulate them from the effects of enacting additional protections for PDMP information. It may be less costly for narcotics agencies to comply with a probable cause requirement, as they are better able to obtain the evidence necessary to demonstrate probable cause. Conversely, narcotics agencies may derive more benefit from obtaining PDMP information, as it is particularly probative of the crimes they investigate.

Regardless of why it occurs, variation across agency types poses a significant challenge to regulation of law enforcement information use. If the goal of regulating law enforcement access to information is at least in part to manage the frequency with which law enforcement obtains that information, then what type of agency should we consider when deciding whether such regulations are necessary or successful? Crafting regulations around specialized agencies that are less sensitive to the changes in cost created by new policies can unduly hamper the ability of nonspecialized agencies to obtain information; regulations crafted around nonspecialized agencies may pose only a weak constraint on use of information by specialized agencies. This is a difficult calculus to perform, and will depend on the specific type of information in question.

Third, this analysis suggests that not all mechanisms for imposing regulatory costs are associated with changes in the rate of law enforcement requests for information ${ }^{10}$ and that, in some cases, mechanisms intended to create regulatory costs may be associated with higher rates of surveillance use. Requiring law enforcement to demonstrate probable cause or obtain a subpoena prior to obtaining PDMP information was associated 
with decreased use of that information; to a lesser extent, requiring law enforcement to connect their request to a particular case was associated with lower PDMP use by law enforcement. However, regulatory mechanisms that do not mandate that law enforcement meet a particular standard every time they requested information did not have a similar effect. Policies requiring restricting information provided and limiting use of PDMP information to narcotics investigations were not associated with a lower rate of PDMP requests by law enforcement. Furthermore, requiring law enforcement to undergo training prior to requesting PDMP information was actually associated with a higher number of requests for PDMP information. While perhaps unexpected, this might be due to training increasing the salience of PDMP information, increasing incentives to use PDMP information (if law enforcement officers feel motivated to use PDMP information to justify their training), or increasing the benefits associated with using PDMP information (if training helps law enforcement officers use PDMP information more effectively.

The different impacts of legal and non-legal regulatory mechanisms on law enforcement behavior may be partially explained by considering the different types of costs imposed by these mechanisms. Some expenses related to obtaining information operate as fixed costs, not varying with the amount of information obtained, while other expenses may operate as variable costs, increasing as the amount of information obtained increases. In this framework, legal mechanisms impose variable costs that must be paid each time PDMP information is requested, while the other regulatory mechanisms impose fixed costs. Consequently, although legislators can employ a variety of mechanisms to 
limit law enforcement use of PDMP data, they should consider the potential efficacy and unintended consequences of the mechanisms they choose.

\footnotetext{
${ }^{1}$ For example, based on the Court's description in Whalen it would appear that New York's PDMP held approximately 6 million prescription records at any time: 100,000 prescriptions were reported per month and records were destroyed after 5 years (Whalen v. Roe, 492 U.S. at 593-4).

${ }^{2}$ This chart was created using data on state PDMP policies compiled by the Prescription Drug Abuse Policy System Legal Science. (2018). "Prescription Drug Abuse Policy System." Retrieved April 20, 2018, 2018, from http://pdaps.org/.

${ }^{3}$ The Prescription Drug Monitoring Program Training and Technical Assistance Center (PDMP TTAC) at Brandeis University conducted a survey of all state PDMPs in 2011-2013, including data on the number of prescription records collected for certain years in certain states. The yearly number of prescription records collected varies from state to state depending on population and other factors; the yearly count ranges from just over 500,000 in Alaska to over 45 million in California. PDMP TTAC. (2018). "State Profiles." Retrieved April 20, 2018, from http://www.pdmpassist.org/content/state-profiles.. Given that most states appear to report yearly numbers in at least the low millions and data are kept for multiple years, hundreds of millions of prescription records would appear to be a conservative estimate.

${ }^{4}$ As 2017 data are not yet available, 2017 values were extrapolated from prior state trends.

${ }^{55}$ As data are available for a one-year period prior to the passage of the law and a six-month period after the passage of the law, I divided the pre-law observations in half so that they represent to a six-month time period.

${ }^{6}$ In Figure 5, the comparison group is comprised of data from Alaska, Arkansas, Florida, Idaho, Iowa, Kentucky, Louisiana, Montana, New Jersey, Ohio, Oregon, South Dakota, Tennessee, Texas, and Wisconsin.

${ }^{7}$ The percent difference describes the change in the number of requests made, normalized by the number of requests made in the pre-law period. A percent difference of $50 \%$ corresponds to an agency making half as many requests in the post-law period as they did in the pre-law period; a percent reduction of $100 \%$ corresponds to an agency making no requests in the post-law period.

${ }^{8}$ Requests made by federal and state agencies were omitted for purposes of this analysis, since they could not be reliably attributed to investigations within a particular county.

${ }^{9}$ Counties are shaded in grey if no data are available on their use of CSD data during this time period.

${ }^{10} \mathrm{It}$ is important to note, however, that mechanisms for imposing regulatory costs that are not associated with changes in the rate with which PDMP information is used may still be associated with other changes in law enforcement behavior that are not observable from this data.
} 


\section{Table of Cases and Statutes}

Brumley v. City of Cleveland, No. E2014-02213-COA-R3-CV (Tenn. Ct. App. Aug. 26, 2015)

Petition for Writ of Certiorari, Carpenter v. U.S., No. 14-1572 (2017)

DEA vs. Utah Department of Commerce, 16-cv-611-DN-DBP (D. Utah Feb. 16, 2016)

Douglas v. Dobbs, 419 F.3d 1097, 1102 (10th Cir. 2005)

Ferguson v. City of Charleston, 532 U.S. 67, 79 (2001)

Katz v. United States, 389 U.S. 347 (1967)

Lewis v. Superior Court of Los Angeles County, 3 Cal.5th (2017)

Oregon Prescription Drug Monitoring Program v. DEA, 998 F. Supp. 2d 957, 966 (2014)

Oregon Prescription Drug Monitoring Program v. DEA, 860 F.3d 1228, 1235 (2017)

Pennsylvania v. Labron, 518 U.S. 938 (1996)

State v. Legrand, 20 A.3d 52 (2011)

State v. Skinner, 10 So. 3d 1212 (La. 2009)

U.S. v. Jones, 132 S.Ct. 945 (2012)

U.S. v. Miller, 425 U.S. 435 (1976)

Whalen v. Roe, 429 U.S. 589 (1977)

U.S. Const. Amend. IV

18 U.S.C. $\S 2703(\mathrm{c})(2)$

Alaska Stat. §17.30.200(d)(5) (2016)

Alaska Stat. § 17.30.200(d) (2017)

Ark. Code $\S 20-7-604$ (2017)

Ariz. Rev. Stat. §36-2604(D)(4) (2017)

CO Rev. Stat. § 12-42.5-404(3)(e) (2016)

Conn. Agencies Regs. § 21a-254-6(a) (2015)

Del. Code Ann. tit. $16 \S 4798(2)$ (d) (2017)

D.C. Mun. Regs. tit. 17, § 10307.4 (2017)

Fla. Stat. § 893.055(7)(c) (2016)

720 Ill. Comp. Stat. § 570/138(d) (2017)

Miss. Code Ann. § 73-21-127(e) (2017)

Neb. Rev. Stat. § 71-2454 (2017)

Nev. Rev. Stat. § 453.141(a) (2017)

New York Pub. Health Law $\S 80.107(\mathrm{k})$ (2017)

Ohio Admin Code 4729-37-08 (2017)

35 Pa. Stat. § 872.9(b) (2017)

Tenn. Code Ann. § 53-10-306(j) (2012)

Texas Health \& Safety Code § 481.076(a)(3) (2018)

Utah Code $\S 37 f-3-301$ (2014)

Utah SB 119 (2015)

Wash. Rev. Code $\$ 70.225 .050(3)(d)(2018)$

W. Va. Code R. §60A-9-5(a) (2017)

Wisc. Admin. Code CSB §44.11(10) (2017) 


\section{Other Sources}

Appriss Health. (2018). "PMP Aware." Retrieved April 24, 2018, from

https://apprisshealth.com/solutions/pmp-aware/.

Bambauer, J. (2014). "Hassle." Mich. L. Rev. 113: 461.

Bankston, K. S. and A. Soltani (2013). "Tiny constables and the cost of surveillance:

Making cents out of United States v. Jones." Yale LF 123: 335.

Blumenschein, K., J. L. Fink III, P. R. Freeman, K. James, K. L. Kirsh, D. I. Steinke and J.

Talber (2010). Review of Prescription Drug Monitoring Programs in the United States, Institute foe Pharmaceutical Outcomes and Policy, Department of Pharmacy Practice and Science, University of Kentucky.

Centers for Disease Control. (2017). "U.S. Prescribing Rate Maps." Retrieved April 20, 2018, 2018, from https://www.cdc.gov/drugoverdose/maps/rxrate-maps.html.

Centers for Disease Control. (2018). "Bridged-Race Population Estimates." from

https://wonder.cdc.gov/bridged-race-population.html.

Centers for Disease Control. (2018). "Underlying Cause of Death 1999-2017 on CDC

WONDER Online Database." from https://wonder.cdc.gov/mcd.html

Commonwealth Fund. (2018). "Status of Medicaid Expansion and Work Requirement

Waivers." from https://www.commonwealthfund.org/publications/maps-and-

interactives/2018/dec/status-medicaid-expansion-and-work-requirement-waivers.

Dasgupta, N., L. Beletsky and D. Ciccarone (2018). "Opioid Crisis: No Easy Fix to Its Social

and Economic Determinants." American journal of public health 108(2): 182-186.

Davis, C. S. (2017). "Commentary on Pardo (2017) and Moyo et al.(2017): Much still

unknown about prescription drug monitoring programs." Addiction 112(10): 1797-1798.

DEA. (2018). "Drug Schedules." Retrieved April 20, 2018, from

https://www.dea.gov/druginfo/ds.shtml.

Deyo, R. A., J. M. Irvine, L. M. Millet, T. Beran, N. O’Kane, D. A. Wright and D. McCarty (2013). "Measures such as interstate cooperation would improve the efficacy of programs to track controlled drug prescriptions." Health Affairs 32(3): 603-613.

Dowell, D., K. Zhang, R. K. Noonan and J. M. Hockenberry (2016). "Mandatory provider review and pain clinic laws reduce the amounts of opioids prescribed and overdose death rates." Health Affairs 35(10): 1876-1883.

Fink, D. S., J. P. Schleimer, A. Sarvet and et al. (2018). "Association between prescription drug monitoring programs and nonfatal and fatal drug overdoses: A systematic review." Annals of Internal Medicine. 
Fishman, S. M. (2004). "Repeal of triplicate prescribing and the new security paper prescription requirement in California." CSA Bulletin: 46-52.

Greenblatt, M. and A. M. Hill (2016). Your prescriptions aren't private: Law enforcement has ways of seeing drug histories. S. News.

Haffajee, R. L. (2015). "Preventing opioid misuse with prescription drug monitoring programs: a framework for evaluating the success of state public health laws." ㄴJ 67: 1621.

Haffajee, R. L., A. B. Jena and S. G. Weiner (2015). "Mandatory use of prescription drug monitoring programs." Jama 313(9): 891-892.

Irvine, J. M., S. E. Hallvik, C. Hildebran, M. Marino, T. Beran and R. A. Deyo (2014). "Who uses a prescription drug monitoring program and how? Insights from a statewide survey of Oregon clinicians." The Journal of Pain 15(7): 747-755.

Israel, J. H. (1971). "Searches without Warrants."

Kam, D. (2013). "“Critics skeptical of Official moves to safeguard Florida prescription database"." Retrieved April 20, 2018, 2018, from

https://www.palmbeachpost.com/news/crime--law/critics-skeptical-official-movessafeguard-florida-prescription-database/CGVEIGy3umx58pDEGEqxfL/.

Kaplan, J. (2018). Uniform Crime Reporting (UCR) Program Data: Arrests by Age, Sex, and Race, 1974-2016. I.-u. C. f. P. a. S. Research.

Kerr, O. S. (2011). "An equilibrium-adjustment theory of the Fourth Amendment." Harv. L. Rev. 125: 476.

Legal Science. (2018). "Prescription Drug Abuse Policy System." Retrieved April 20, 2018, 2018, from http://pdaps.org/.

Mandell, B. F. (2016). "The fifth vital sign: A complex story of politics and patient care." Cleveland Clinic journal of medicine 83(6): 400.

Meinhofer, A. and A. E. Witman (2018). "The role of health insurance on treatment for opioid use disorders: Evidence from the Affordable Care Act Medicaid expansion." Journal of health economics 60: 177-197.

Mejia, J. (2014). Brief of Amici Curiae, American Civil Liberties Union, in Support of Defendant's Motion to Suppress.

Minzner, M. and C. M. Anderson (2013). "Do Warrants Matter?" Review of Law \& Economics 9(2): 169-196.

Office of the Legislative Auditor General (2015). A Review of the Use of the Controlled Substance Database by Law enforcement.

Ohm, P. (2009). "Probably Probable Cause: The Diminishing Importance of Justification Standards." Minn. L. Rev. 94: 1514.

Pardo, B. (2017). "Do more robust prescription drug monitoring programs reduce prescription opioid overdose?" Addiction 112(10): 1773-1783.

Paulozzi, L. J., E. M. Kilbourne and H. A. Desai (2011). "Prescription drug monitoring programs and death rates from drug overdose." Pain medicine 12(5): 747-754. 
PDMP TTAC. (2017). "Drugs Monitored by PDMP." Retrieved April 20, 2018, from http://www.pdmpassist.org/pdf/PDMP Substances Tracked 20171205.pdf. PDMP TTAC. (2017). "Interstate Data Sharing." Retrieved April 24, 2018, from http://www.pdmpassist.org/pdf/Interstate_Data_Sharing_20170920.pdf. PDMP TTAC. (2018). "State Profiles." Retrieved April 20, 2018, from http://www.pdmpassist.org/content/state-profiles.

PDMP TTAC (2018). Technical Assistance Guide: Prescription Drug Monitoring Programs Administrators' Orientation Package.

PDMP TTAC. (2018). "Utah State Profile." Retrieved April 20, 2018, from http://www.pdmpassist.org/content/utah-state-profile.

Perez, N. M., W. G. Jennings, Y. Wang and C. Delcher (2017). "Law Enforcement Officers' Perceptions of Florida's Prescription Drug Monitoring Program." Journal of Contemporary Criminal Justice 33(4): 368-379.

Reifler, L. M., D. Droz, J. E. Bailey, S. H. Schnoll, R. Fant, R. C. Dart and B. Bucher Bartelson (2012). "Do prescription monitoring programs impact state trends in opioid abuse/misuse?" Pain Medicine 13(3): 434-442.

Rudd, R. A., N. Aleshire, J. E. Zibbell and R. Matthew Gladden (2016). "Increases in drug and opioid overdose deaths-United States, 2000-2014." American Journal of Transplantation 16(4): 1323-1327.

Schwartzapfel, B. (2017). "Guess Who's Tracking Your Prescription Drugs?" The Marshall Project Retrieved April 20, 2018, from

https://www.themarshallproject.org/2017/08/02/guess-whos-tracking-yourprescription-drugs.

Silver Sweeney, M. (2015). The big drug database in the sky: One firefighter's year-long legal nightmare. Ars Technica.

Sinnenberg, L. E., K. J. Wanner, J. Perrone, F. K. Barg, K. V. Rhodes and Z. F. Meisel (2017). "What Factors Affect Physicians' Decisions to Prescribe Opioids in Emergency Departments?" MDM Policy \& Practice 2(1): 2381468316681006.

Slobogin, C. (2003). An empirically based comparison of American and European regulatory approaches to police investigation. Adversarial versus Inquisitorial Justice, Springer: 27-54.

Slobogin, C. (2011). "Comparative Empiricism and Police Investigative Practices." NCJ Int'I L. \& Com. Reg. 37: 321.

Smith, R. J., A. S. Kilaru, J. Perrone, B. Paciotti, F. K. Barg, S. M. Gadsden and Z. F. Meisel (2015). "How, why, and for whom do emergency medicine providers use prescription drug monitoring programs?" Pain Medicine 16(6): 1122-1131.

Unger, D. T. (2014). "Minding Your Meds: Balancing the Needs for Patient Privacy and Law Enforcement in Prescription Drug Monitoring Programs." W. Va. L. Rev. 117: 345. White House. (2018). "President Donald J. Trump's Initiative to Stop Opioid Abuse and Reduce Drug Supply and Demand." Retrieved April 20, 2018, 2018, from 
https://www.whitehouse.gov/briefings-statements/president-donald-j-trumps-

initiative-stop-opioid-abuse-reduce-drug-supply-demand/.

Whitehurst, L. (2017). Utah to obey order for DEA drug database search. Salt Lake

Tribune.

Worley, J. (2012). "Prescription drug monitoring programs, a response to doctor shopping: purpose, effectiveness, and directions for future research." Issues in mental health nursing 33(5): 319-328. 